Adsorption Of Heavy Metals From Groundwater Using Titanate Nanoparticles Doped With Cross-Linked Polyvinyl Alcohol. Bahr El-Baqar Drain Region, ElHusinia, East Delta-Egypt

\author{
Ahmed M. Desouky, Mohamed E.A. Ali and Ehab Zaghlool
}

Desert Research Center, Cairo, Egypt.

Received: 20 Mar. 2020 / Accepted 10 July 2020 / Publication date: 20 July 2020

\begin{abstract}
A composite of polyvinyl alcohol (PVA) and titanate nanoparticles (TNTs) was cross-linked with epichlorohydrin (EP) following the inverse-suspension polymerization method. Controlling the ratio of EP:PVA as well as the crosslinking time produces spherical beads, which characterized by scanning electron microscope (SEM) and Fourier transform infrared spectroscopy (FTIR). The factors affecting the maximum adsorption capacity of PVA/ TNTs against ferrous ion were investigated. The kinetic of the adsorption process were better fitted by the pseudo-second-order model than pseudo-first-order model. The equilibrium adsorption data were analyzed with isotherm models (Langmuir model, Freundlich model). The study showed that PVA/TNTs has high potential for removing iron ions from polluted water. In the present study, the removal of $\mathrm{Fe}^{+2}$ from aqueous solution by our resin was investigated. synthesized resin were investigated by SEM and IR. Initial $\mathrm{pH}$ also affected the removal process and the optimum initial $\mathrm{pH}$ was 5 . The kinetic data were better described by the pseudo-secondorder model than by the pseudo-first-order model. The equilibrium adsorption data were analyzed with two isotherm models (Langmuir model, Freundlich model).
\end{abstract}

Keywords: Groundwater contamination, Polyvinyl alcohol, Titanate, Adsorption, Titanate nanotubes (TNTs)

\title{
Introduction
}

Water is one of the essential factors for the development of humanity. Increasing water scarcity and environmental considerations are calling for more effective means to purify industrial and urban wastewaters (El Saliby, 2012). It is estimated that millions of people in the world are exposed to the presence of pollution in drinking water, in concentrations harmful to health (Rocío et al., 2019). Adsorption processes are able to effectively remove many persistent and toxic pollutants from water to enable the use and reuse of impaired quality raw water sources (El Saliby, 2012). Recent advances in nanotechnology offer leap frogging opportunities to develop next-generation water supply systems. The present water treatment, distribution, and discharge practices, which heavily rely on conveyance and centralized systems, are no longer sustainable (Qu et al., 2013). The highly efficient, modular, and multifunctional processes enabled by nanotechnology are envisaged to provide high performance, affordable water and wastewater treatment solutions (Qu et al., 2013). PVA is a synthetic water-soluble hydrophilic polymer, the basic properties of PVA are dependent on the degree of polymerization or the degree of hydrolysis (Peppas et al., 2000). It has been widely used in adhesives, emulsificants, textile and paper industry applications and in the attainment of amphiphilic membranes for enzyme immobilization and as a base polymer for wastewater treatment (Peppas et al., 2000). Vinyl polymers are derived from vinyl monomers containing double bonds $\mathrm{C}=\mathrm{C}$. The main chain of polymer is made from carbon atoms containing single bonds, to which other substituents can be added such as chlorine, titanate, fluorine or hydroxyl group (PAJĄK et al., 2010). High hyrophilicity of PVA making it a good polymer for adsorption processes (Mranda et al., 2001). Because of its large surface area and strong ion exchange capacity, titanate nanomaterials have a wide range of applications in many fields such as adsorption, photovoltaics and so on. However, studies at home and abroad in recent years have shown that the prepared titanate nanoparticles are easily agglomerated (Xie et al., 2017). Preparation of titanate nanotubes (TNTs) as small as $10 \mathrm{~nm}$ by a simple hydrothermal treatment of $\mathrm{TiO}_{2}$ powder in presence of sodium hydroxide aqueous solution provided shorter time for synthesis with high yield and reusable alkali solutions (Niu et al., 2009 and Xiong et al., 2011). In recent years, TNTs have been proved to be

Corresponding Author: Ehab Zaghlool, Desert Research Center, Cairo, Egypt.

E-mail: ezaghlooldrc@yahoo.com 
an efficient for the adsorption of dyes(Lee et al., 2007; Lee et al., 2008 ${ }^{\mathrm{a}}$; Lee et al., $2008^{\mathrm{b}}$ and Xiong et al., 2010), heavy metals (Liu et al., 2013 and Sheng et al., 2014), and even radionuclides (Sheng et al., 2013 and Sheng \&Hu 2013).

To the best of our knowledge, the studies about the removal of heavy metals by TNTs adsorption are still scarce. Therefore, in this work TNTs doped with cross-linked PVA was prepared, characterized and used as an adsorbent for the ferrous ion from a natural contaminated water samples that collected from some drains.

\section{Site description:}

The study area is located in the Eastern part of River Nile Delta region, Egypt. The area lies between latitude $30.752^{\circ}$ to $30.950^{\circ} \mathrm{N}$ and longitude $31.800^{\circ}$ to $32.050^{\circ} \mathrm{E}$, covers approximately 600 $\mathrm{km}^{2}$ area (Fig.1). Bahr El-Baqar drain is one of the most contaminated surface water features in the study area. Manzala Lake is recharged from Bahr El-Baqar drain by about $2.3 \mathrm{BCM} / \mathrm{year}$. The west water resources of Bahr El-Baqar drain is from treated sewage from El-Gabal El-Asfar and El-Berka Wastewater Treatment Plants, Industrial Wastewater both treated and raw from the Greater Cairo City and Land drainage of a cultivated area which is more than 1.2 million feddans (El-Kiki 2018).

The study area is characterized by a hot climate in the summer and a short rainy winter with moderate humidity. The annual rainfall varies from 20 to $100 \mathrm{~mm} /$ year (Dahab et al., 2007 and RIGWIWACO., 1992). The area is characterized by low relief bounded by a moderately elevated plateau. The area is occupied by sedimentary Quaternary rocks (Geriesh 1994). The Quaternary aquifer is composed of sand and sandstone with intercalations of clay (old deltaic deposits) and aeolian deposits (Moussa 1990). The western and middle parts are strongly affected by deep-seated normal faults where saline water of Miocene aquifer moves upward along the fault planes (Gad 1995).

The Quaternary aquifer constitutes the main groundwater source in the study area. The groundwater exists mostly under unconfined condition. However locally confined to semi-confined conditions may exist due to the muddy flood plain sediments, which cover the aquifer at some localities. The Quaternary aquifer thickness is affected by set faults which increases the aquifer thickness towards the north. The aquifer thickness varies from 300 to $400 \mathrm{~m}$ (Gomaah et al., 2016). The general flow direction is from the southwest to northeast towards Manzala Lake.

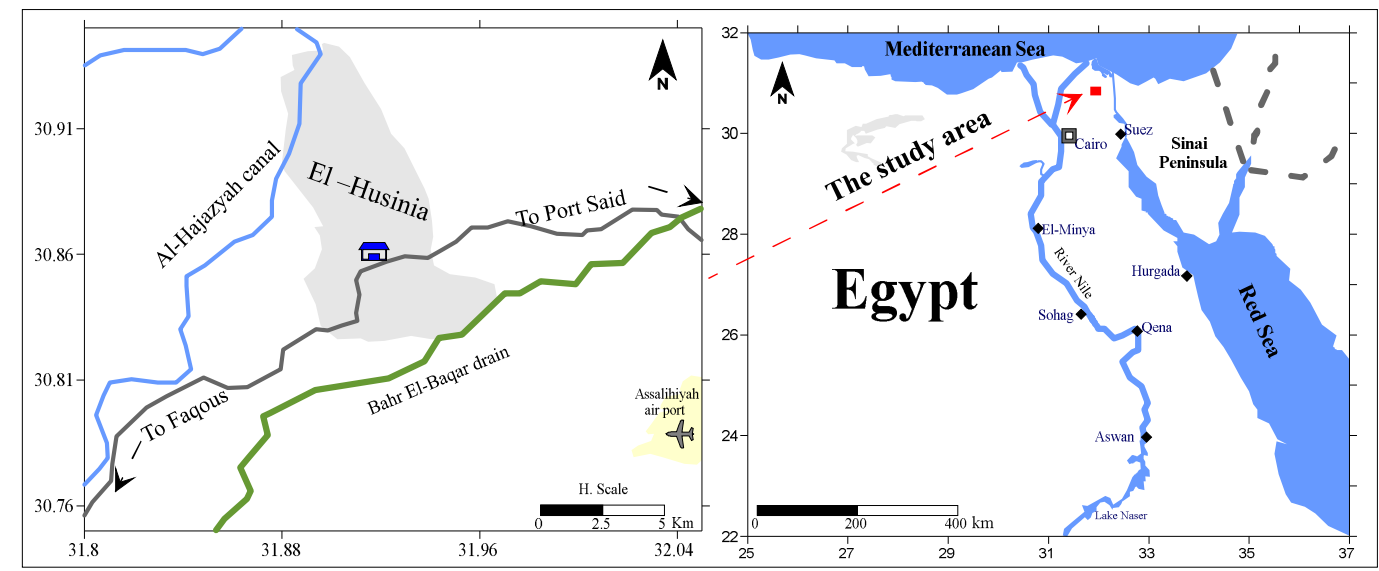

Fig. 1: The location map of the study area.

The isotopic signature $\left(\delta^{18} \mathrm{O}, \delta^{2} \mathrm{H}\right.$ and $\left.\delta^{15} \mathrm{~N}\right)$ of the Pleistocene groundwater indicated that the contamination source in the study area is originated from direct infiltration of the surface water (Irrigation canals, agricultural drains and Bahr-El Baqar sewage drain). The sewage disposal, mineral fertilizer, septic tanks and Bahr El-Baqar sewage drain are the main sources of the groundwater contamination (Eissa et al., 2019). Co, $\mathrm{Zn}$ and $\mathrm{Cu}$ metals have significant loading factor and their variability imply large impacts on the groundwater quality. 


\section{Materials and Methods}

\section{Materials}

Polyvinyl alchol,titanate (Aldrich Company), epichlorohydrin (EP) (El-Nasr company), sodium hydroxide,ferrous sulfate Mollin Ckrodt Company of purity $97 \%$ was used as received. The other chemicals, such as inorganic salts used without further purification.

\section{Methods}

\subsection{Groundwater sampling and analysis}

The water chemistry data in this paper collected from the analysis data of 19 Pleistocene groundwater samples and previous studies in the Eastern Nile Delta (Eissa et al., 2019 and Abdelrazek 2019). The groundwater samples were collected during June 2019. The Pleistocene groundwater samples were preserved by acidifying to $\mathrm{pH}<2$ with $\mathrm{HNO}_{3}$ in a $50 \mathrm{ml}$ pre-cleaned polypropylene bottles. Heavy metal ions were measured by using inductive coupled plasma mass spectrometry (ICP, POEMSIII, thermo Jarrell elemental company USA). The water samples were analyzed in the Hydrogeochemistry Dept., lab, Desert research center, Egypt.

\subsection{Preparation of PVA/TNTs}

Essentially, the first step (pre-crosslinking) is performed by adding aqueous solution of PVA and titanate nanotubes were then prepared as additives with stirring for $24 \mathrm{hrs}$. Then add epichlorohydrin (EP) to the solution containing sodium hydroxide at $50 \mathrm{C}^{\mathrm{o}}$ Pre-crosslinking is allowed to proceed until a certain viscosity is reached, which is deemed appropriate for bead preparation. In the second step, the solution is suspended in paraffin oil with a surfactant under vigorous and controlled stirring (400 rpm). Crosslinking is allowed to proceed in the stirred paraffin oil for $24 \mathrm{hrs}$ at $50 \mathrm{C}^{\circ}$.

\subsection{Characterization}

Infrared spectroscopy was carried out using Gensis Unicam FT-IR spectrophotometer by incorporating the sample in a $\mathrm{KBr}$ disk. Scanning electron micrographs (SEM), Quanta FEG 250 microscope.

\subsection{Batch adsorption experiment}

Applicability of PVA/TNTs for Fe(II) removal was studied using batch experiments in a reaction mixture of $0.1 \mathrm{~g}$ of adsorbent and $0.025 \mathrm{~L}$ of metal solution containing $\mathrm{Fe}(\mathrm{II})$ at concentrations ranging from 200 to $1000 \mathrm{mgL}^{-1}$. The effect of $\mathrm{pH}$ was studied at metal concentration of $1000 \mathrm{mgL}-1$ in the $\mathrm{pH}$ range of 2-5. The effect of contact time was studied at metal concentrations of 200 and $100 \mathrm{mgL}^{-1}$. Agitation was undertaken using a rotary shaker type SK 300 (Lab companion). At designated contact time, the adsorbent was separated from the solution. The metal concentrations in the filtrates were analyzed by Atomic Absorption Spectrophotometer, (Unicam model Solaar 929. The adsorption capacities $\left(\mathrm{mg} \mathrm{g}^{-1}\right)$ of PVA/TNTs were calculated as follows:

$$
\mathrm{q}_{\mathrm{e}}=\left(\mathrm{C}_{\mathrm{i}}-\mathrm{C}_{\mathrm{e}}\right) \mathrm{V}(\mathrm{L}) / \mathrm{W}
$$

Where $\mathrm{Ci}$ and $\mathrm{Ce}$ are the initial and the equilibrium concentrations, respectively $\left(\mathrm{mg} \mathrm{L}^{-1}\right)$, while $\mathrm{W}(\mathrm{g})$ and $\mathrm{V}(\mathrm{L})$ represent the weight of the adsorbent and the volume of the solution, respectively.

\section{Results and discussion}

\section{Heavy Metals and Pollution Assessment.}

A number of researchers have evaluated the quality of the water resources in Bahr El-Baqar drain region and its vicinities based on the major, trace and heavy metals constituents as well as stable isotopes to evaluate both of surface and groundwater quality (El Arabi et al., 2013) . Generally the concentration of heavy metals in Bahr El-Baqar drain water followed the order $\mathrm{Fe}>\mathrm{Zn}>\mathrm{Mn}>\mathrm{Cu}>\mathrm{Pb}>\mathrm{Ni}>\mathrm{Cd}$. The heavy metals concentration in Bahr El-Baqar drain water recorded significant increases per time from the year 2015 to 2018 in the same site $\left(31.198^{0} \mathrm{~N}, 32.252^{0} \mathrm{E}\right)$. Cd concentration increases from 12.99 to $14.69 \mathrm{mg} / \mathrm{l}$, Co from 86.78 to $89.72 \mathrm{mg} / \mathrm{l}, \mathrm{Cu}$ from 63.85 to 65.70 
$\mathrm{mg} / \mathrm{l}$, Fe from 44.36 to $47.45 \mathrm{mg} / \mathrm{l}, \mathrm{Mn}$ from 55.76 to $58.98 \mathrm{mg} / \mathrm{l}$, Ni from 65.97 to $73.22 \mathrm{mg} / \mathrm{Pb}$ from 33.91 to $36.64 \mathrm{mg} / \mathrm{l}$ and $\mathrm{Zn}$ from 87.97 to $90.56 \mathrm{mg} / \mathrm{l}$ (Abdelrazek, 2019).

The heavy metals concentrations of the Pleistocene groundwater samples (Table 1) reflects that $100 \%$ of the water samples are under the drinking water guideline $\mathrm{WHO}(2011)$ in respect to $\mathrm{Cd}, \mathrm{Cu}$, $\mathrm{Ni}$ and $\mathrm{Zn}$. the Pleistocene groundwater samples are contaminated in respect to $\mathrm{Al}, \mathrm{Cr}, \mathrm{Fe}, \mathrm{Mn}$ and $\mathrm{Pb}$ (37\%, 5\%, 16\%, 32\% and $21 \%$ respectively) (El-Eweddy, 2000 ).

Table 1: Heavy Metals concentrations of the Pleistocene groundwater in the study area ( $\mathrm{mg} / \mathrm{l})$.

\begin{tabular}{cccccccccc}
\hline No. & $\mathbf{A l}$ & $\mathbf{C d}$ & $\mathbf{C r}$ & $\mathbf{C u}$ & $\mathbf{F e}$ & $\mathbf{M n}$ & $\mathbf{N i}$ & $\mathbf{P b}$ & $\mathbf{Z n}$ \\
\hline $\mathbf{1}$ & 0.055 & 0.001 & 0.0363 & 0.0742 & 0.2361 & 0.2822 & 0.0057 & 0.0106 & 0.0102 \\
$\mathbf{2}$ & 0.6389 & 0.001 & 0.02 & 0.01 & 0.2219 & 0.5941 & 0.0034 & 0.005 & 0.0007 \\
$\mathbf{3}$ & 0.2838 & 0.001 & 0.02 & 0.01 & 0.2125 & 0.8061 & 0.0013 & 0.0049 & 0.0056 \\
$\mathbf{4}$ & 0.06 & 0.001 & 0.02 & 0.08028 & 0.1301 & 0.8953 & 0.0032 & 0.0071 & 0.0045 \\
$\mathbf{5}$ & 0.06 & 0.001 & 0.02 & 0.01 & 0.1607 & 0.2769 & 0.0022 & 0.0153 & 0.1792 \\
$\mathbf{6}$ & 0.4403 & 0.001 & 0.02 & 0.0457 & 0.2125 & 0.7126 & 0.0017 & 0.0117 & 0.0029 \\
$\mathbf{7}$ & 0.6329 & 0.001 & 0.02 & 0.06 & 0.1466 & 0.3473 & 0.0017 & 0.006 & 0.0052 \\
$\mathbf{8}$ & 0.4523 & 0.001 & 0.0516 & 0.0828 & 0.1725 & 0.2658 & 0.0045 & 0.0033 & 0.0521 \\
$\mathbf{9}$ & 0.0972 & 0.001 & 0.02 & 0.0071 & 0.2078 & 0.1099 & 0.0013 & 0.0034 & 0.006 \\
$\mathbf{1 0}$ & 0.2657 & 0.001 & 0.02 & 0.1614 & 0.3044 & 0.1293 & 0.0009 & 0.01 & 0.373 \\
$\mathbf{1 1}$ & 0.1544 & 0.001 & 0.02 & 0.01 & 0.3821 & 0.2488 & 0.0025 & 0.0026 & 0.0126 \\
$\mathbf{1 2}$ & 0.06 & 0.001 & 0.02 & 0.1599 & 0.0194 & 0.4749 & 0.003 & 0.0068 & 0.0044 \\
$\mathbf{1 3}$ & 0.06 & 0.001 & 0.02 & 0.01 & 0.1583 & 0.0057 & 0.0017 & 0.0078 & 0.399 \\
$\mathbf{1 4}$ & 0.6419 & 0.001 & 0.02 & 0.0014 & 0.1277 & 0.2528 & 0.0034 & 0.0058 & 0.0386 \\
$\mathbf{1 5}$ & 0.06 & 0.001 & 0.02 & 0.01 & 0.1654 & 0.139 & 0.0057 & 0.0061 & 0.0027 \\
$\mathbf{1 6}$ & 0.1935 & 0.001 & 0.049 & 0.01 & 0.2196 & 0.0538 & 0.0014 & 0.0029 & 0.0089 \\
$\mathbf{1 7}$ & 0.0279 & 0.001 & 0.02 & 0.0714 & 0.0948 & 0.2809 & 0.0025 & 0.0084 & 0.0053 \\
$\mathbf{1 8}$ & 0.06 & 0.001 & 0.02 & 0.0042 & 0.4386 & 0.4251 & 0.0041 & 0.013 & 0.0354 \\
$\mathbf{1 9}$ & 0.1092 & 0.001 & 0.02 & 0.0471 & 0.1183 & 0.0845 & 0.0053 & 0.0109 & 0.0456 \\
\hline
\end{tabular}

\section{Characterization of the prepared beads}

The SEM images of PVA and PVA/TNTs are shown in (Fig.2). Figure 2 (a) of the cross-linked PVA showed smooth surface with the micro porous structure compared to non-smooth surface of crosslinked polyvinyl alcohol doped with titanate nanoparticles that indicates the strong interaction between PVA/TNTs molecules. Compared to the pure cross-linked PVA, (Fig. 2 (b)). In addition there are different features, where the surface is irregular and rough with increasing the microporous structure, the pore openings and cavities have showed in fig. 1 (b) enhance the adsorption kinetics.
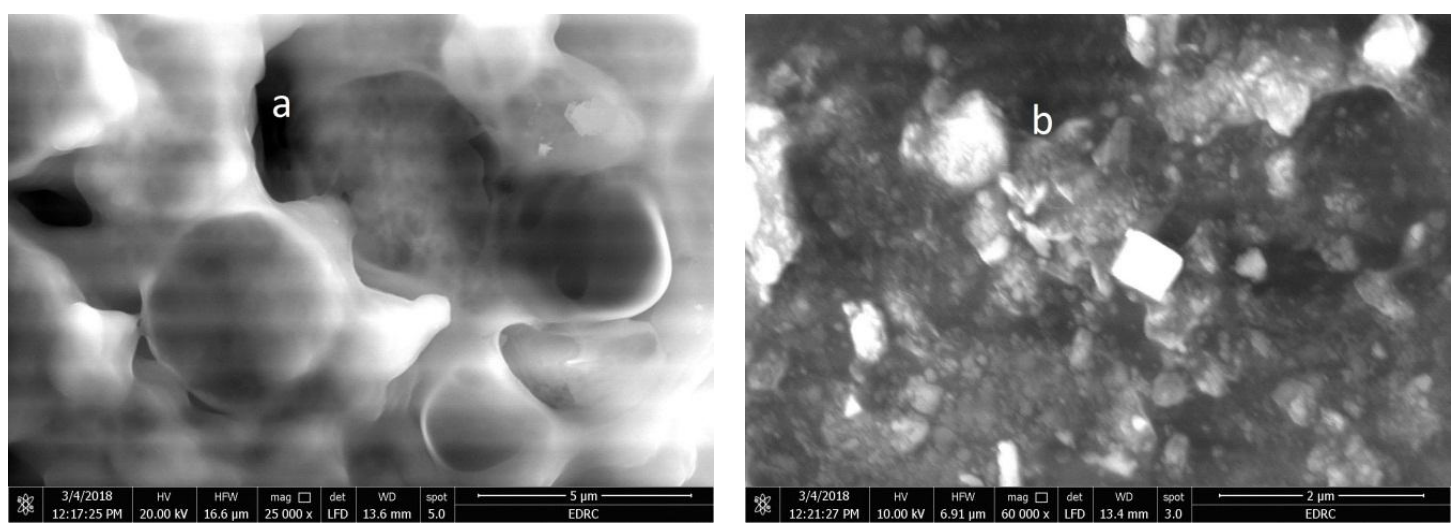

Fig. 2: SEM micrographs of a. crosslink ink PVA, b.TNT with crosslink ink PVA.

FTIR spectra for crosslinking PVA, titanate nanotubes with crosslinking PVA are shown in Fig. 3. The following changes in the spectral features have been observed after comparing the spectrum of complexed PVA with that of crosslinking PVA and titanate nanotubes. The inter molecular hydrogen bonded $\mathrm{O}-\mathrm{H}$ stretching frequency of crosslinking PVA appearing in the range of $3459-3044 \mathrm{~cm}^{-1}$ is shifted to $3273-2919 \mathrm{~cm}^{-1}$, in the modified PVA respectively. In addition to this, the $\mathrm{C}-\mathrm{H}$ stretching of 
$\mathrm{CH}_{2}$ exhibited at $1450 \mathrm{~cm}^{-1}$ in crosslinking PVA is shifted to $1445 \mathrm{~cm}^{-1}$ in the modified PVA, respectively upon doping. and $1058 \mathrm{~cm}^{-1}$ (C-O stretching) is shifted to $1090 \mathrm{~cm}^{-1}$.

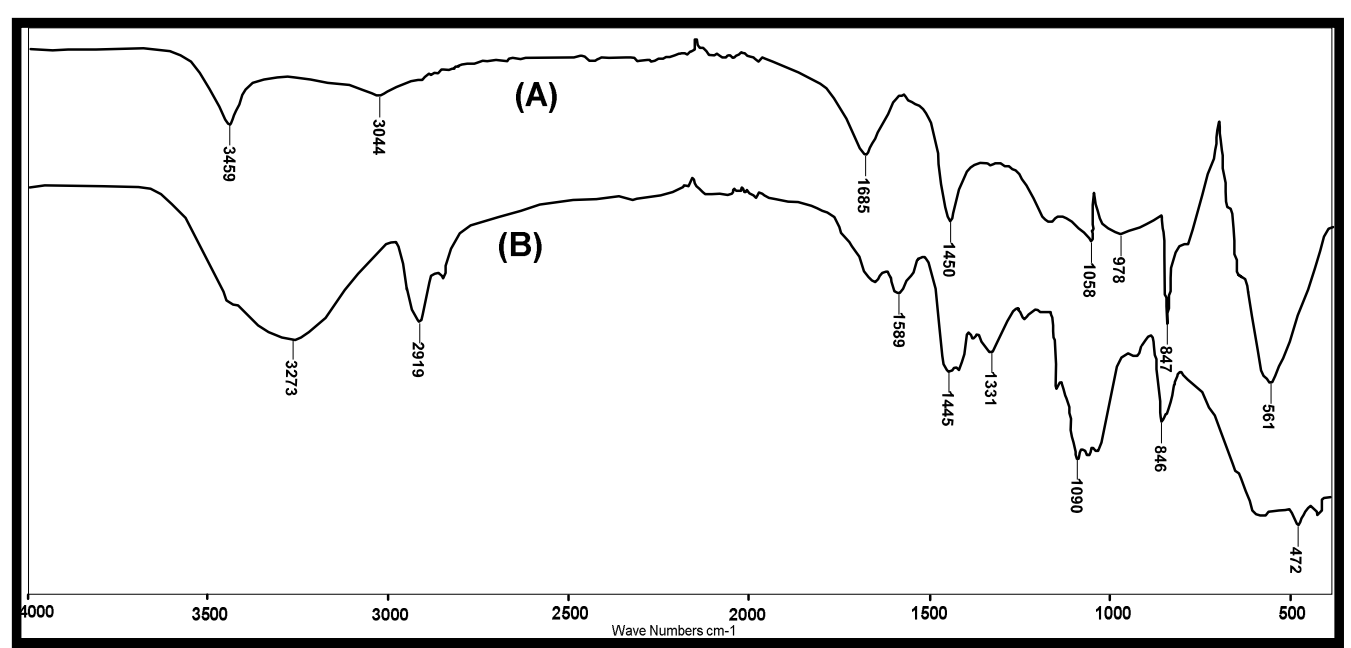

Fig. 3: IR shows of the samples (A)PVA and (B)PVA-TiO ${ }_{2}$

The residual acetate groups in the polymer exhibited peaks at $1685 \mathrm{~cm}^{-1}$ (acetate $\mathrm{C}=\mathrm{O}$ stretching), is shifted to $1589 \mathrm{~cm}^{-1}$ the stretching vibration peak of Ti-O and Ti-O-Ti are near $472 \mathrm{~cm}^{-1}$. All these changes in the FTIR spectra are clear indications for the drafting of crosslinking PVA (Huiyuan et al., 2015).

\section{Factors affecting adsorption of heavy metal ions}

\subsection{Effect of $\mathbf{p H}$}

The $\mathrm{pH}$ of a solution strongly affects the adsorption capacity of our resin, so the effect of solution $\mathrm{pH}$ on metal ions removal after socking of $24 \mathrm{hr}$. was studied at $\mathrm{pH}$ ranges of $2-5$, by adjusting the solution $\mathrm{pH}$ using $0.1 \mathrm{~N} \mathrm{HCl}$ or $0.1 \mathrm{~N} \mathrm{NaOH}$. It is important to mention that, our resin is not stable at strong acidic medium, so its adsorption behavior was studied at $\mathrm{pH}$ ranges from 2-5 (Desouky 2018). Figure 4 shows the effect of $\mathrm{pH}$ on the individual adsorption of $\mathrm{Fe}$ (II) our resin beads. The adsorption increases with increasing the $\mathrm{pH}$ value up to 5 where the maximum adsorption was obtained.

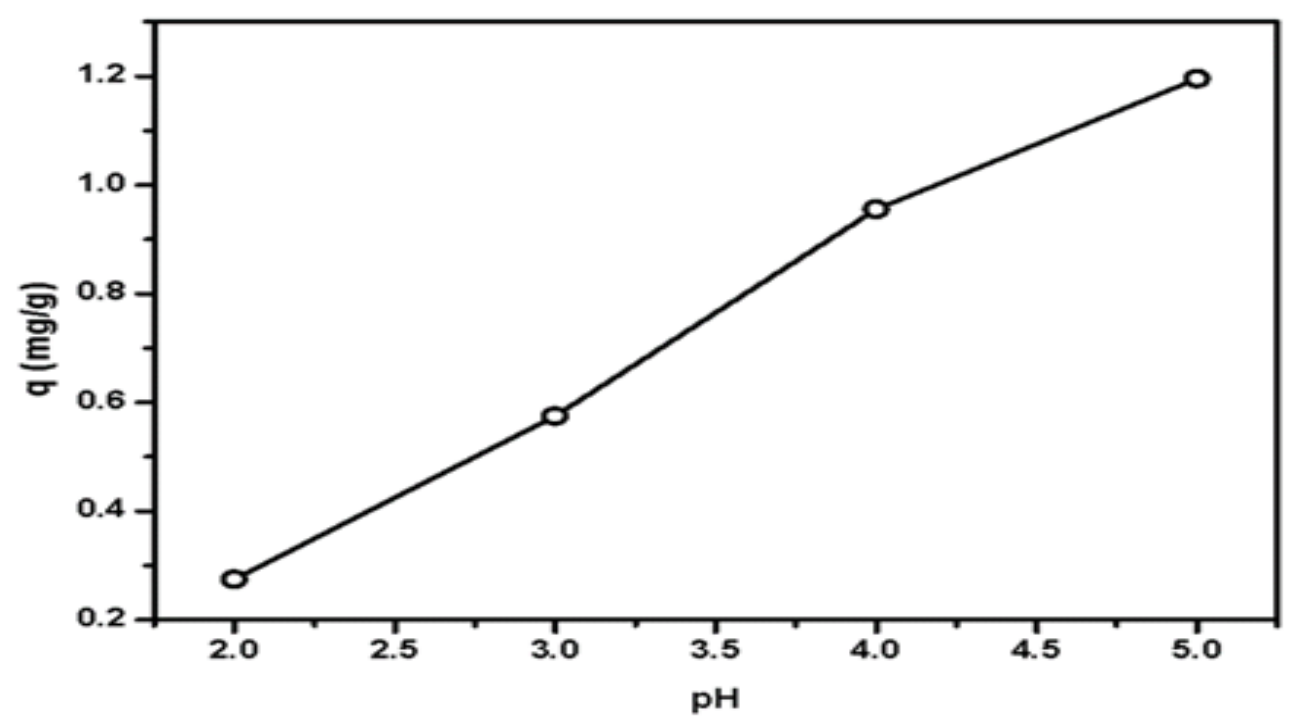

Fig. 4: pH-dependent metal uptake of metal ion 
The low adsorption of metal ions in strong acidic $\mathrm{pH}$ solution (at low $\mathrm{pH}$ ) could be mainly due to the electrostatic repulsion between the positive metal ions $\left(\mathrm{M}^{+}\right)$in the medium and the positive charges in highly acidic solution $\left(\mathrm{H}^{+}\right)$which accumulate on the surface of our resin. In the other words, the functional groups in our resin are easily form protonation, reducing the number of binding sites available for the adsorption of heavy metal ions. This leads to the inducing an electrostatic repulsion of the different heavy metal ions. Therefore, the competition existed between protons and the metal ions $\left(\mathrm{M}^{+}\right)$for adsorption sites and adsorption capacity was decreased. Such repulsion prevents the approach of the metal ions to the beads surface.

While at higher $\mathrm{pH}$ value, the adsorption of heavy metal ions increases due to the weaker electrostatic repulsion, and with the increase of $\mathrm{pH}$ value, the functional groups are free from protonation. Such positive charge density decreases allowing the metal ions to approach the different sorbent beads surface which result in higher adsorption values. The adsorption mechanism may be partially replaced by a chelation mechanism on the functional groups of the different beads and cation exchange. Further increase in the $\mathrm{pH}$ value more than 5 would transform the dissolved metal into precipitated hydroxide form thus the adsorption capacity is decreased. This is well $\mathrm{Fe}^{2+}$ agreement with the previous works (Desouky 2018).

The effects of contact time on the removal of Fe (II) by Ti-PVA is depicted in Fig. 5. Initially the metal uptake was fast due to the many vacant adsorption sites, all the active sites were occupied by target $\mathrm{Fe}$ (II) within $3 \mathrm{hrs}$ after which the adsorption rate gradually decreased and became almost constant at equilibrium to attain equilibrium conditions where the concentration of adsorbate in the bulk solution was in dynamic balance with that at the interface. It is possible that some of the adsorption sites of Ti-PVA was easily obtained due to increases of the functional groups on its surface.

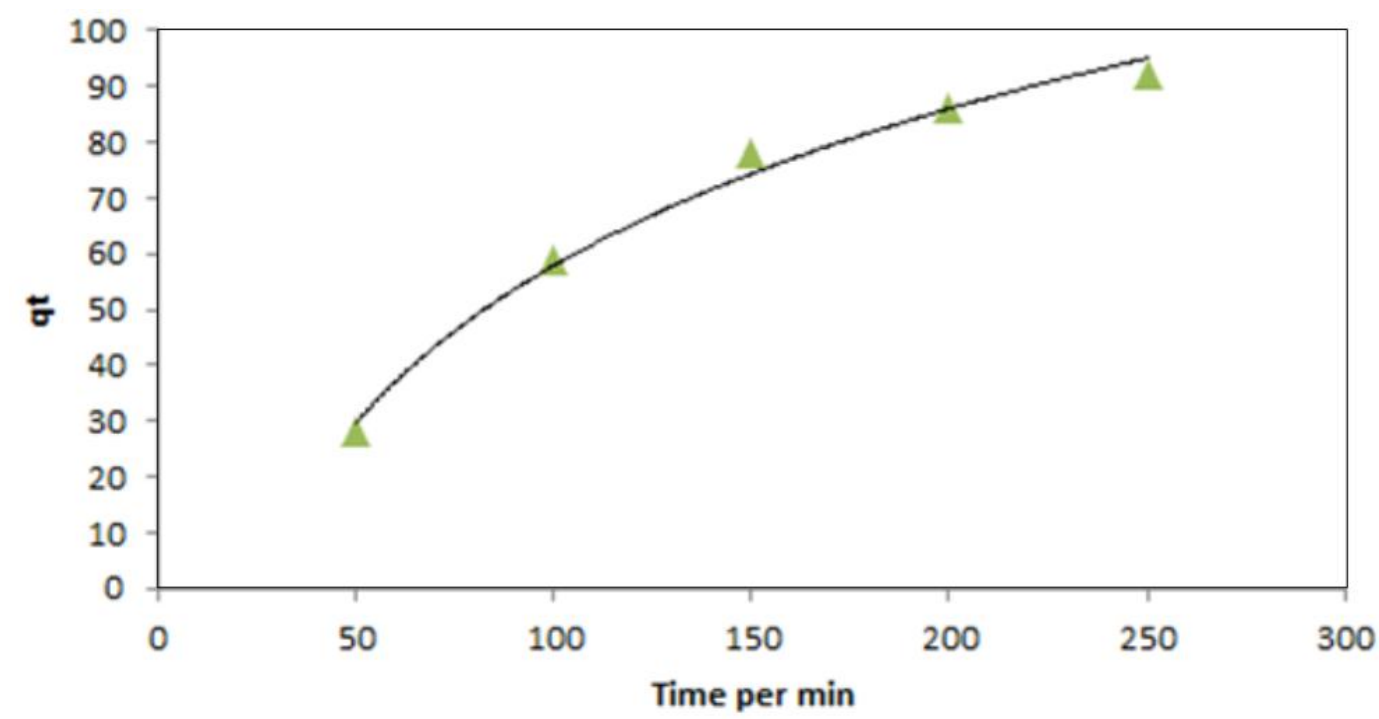

Fig. 5: metal uptake of metal ion with time.

The influence of contact time on the adsorption of ferrous ions on Ti-PVA was investigated at various initial concentrations of 200, 400, 600, 800 and $1000 \mathrm{mg} / \mathrm{l}$ is shown in Fig.6.a. Our experiments were carried out in pure aqueous solution at a fixed adsorbent dose $0.1 \mathrm{~g}$ and $25^{\circ} \mathrm{C}$. It can be seen that by increasing the initial concentration of Fe(II) from 200 to $1000 \mathrm{mg} / \mathrm{l}$, an increase of adsorption capacity as shown in Fig.5a for Ti-PVA. This may be attributed by the initial concentration which provides an important driving force to overcome all mass transfer resistances of the metal ions between the aqueous and solid phases, hence a higher initial concentration of metal solution will enhance the adsorption process, while the percent $\mathrm{Fe}^{2+}$ removal of these ions showed the opposite trend. When the initial concentration increased from 200 to $1000 \mathrm{mg} / \mathrm{L}$, removal percent $\mathrm{Fe}^{2+}$ decreased from $41 \%$ to $19 \%$ for Fe-resin this is due to the saturation of the active sites in the solution. 

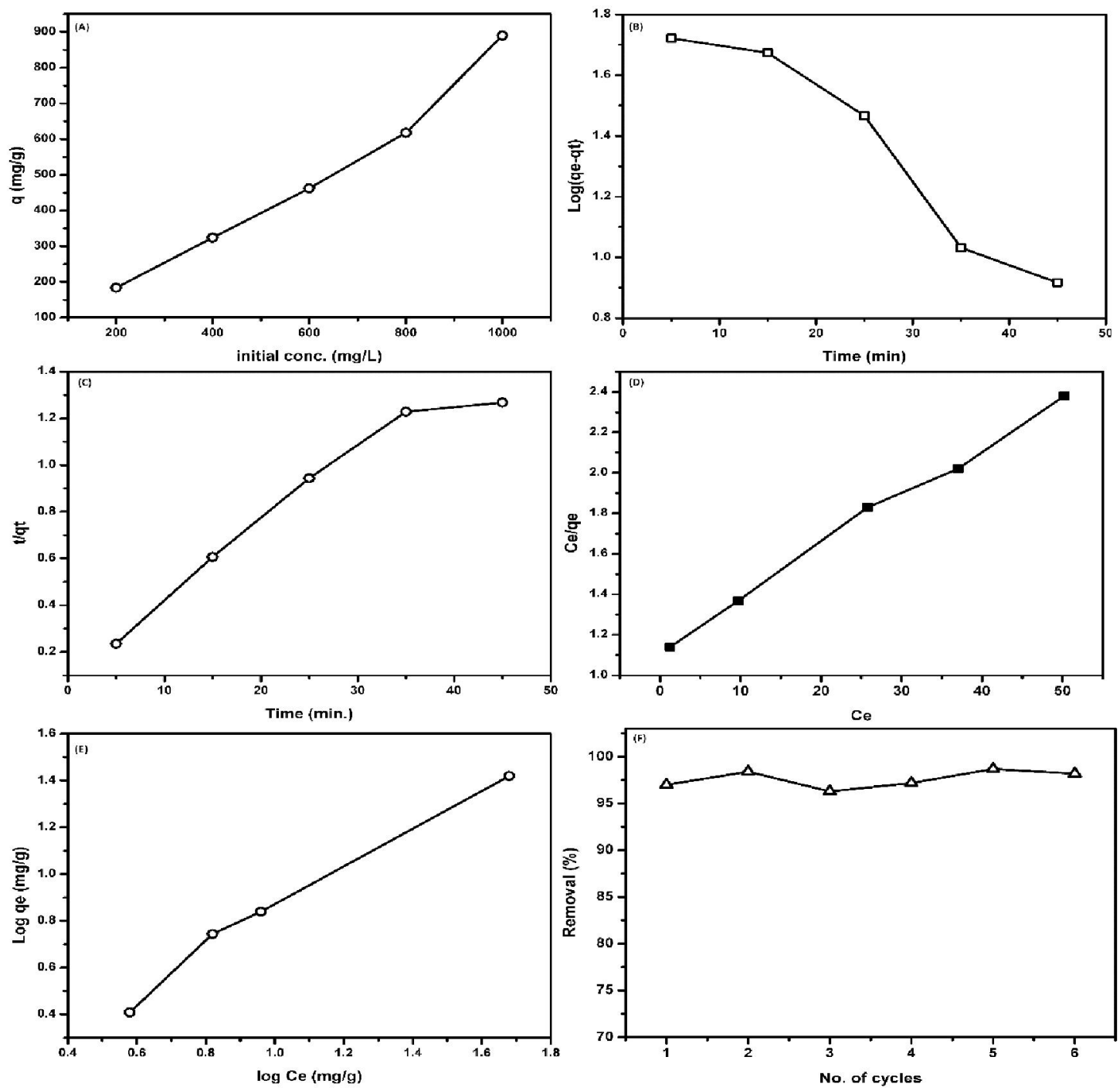

Fig. 6: (a,b,c,d,e,f). The influence of contact time on the adsorption of ferrous ions

\section{Sorption kinetics:}

The uptake-time data obtained were treated in the form of two simplified kinetic models including pseudo first-order and pseudo second order. The pseudo first order model is expressed as:

$$
\log \left(\mathrm{q}_{\mathrm{e}}-\mathrm{q}_{\mathrm{t}}\right)=\log \left(\mathrm{q}_{\mathrm{e}}\right)-\mathrm{k}_{1} \mathrm{t} / 2.303
$$

Where $\mathrm{q}_{\mathrm{e}}$ and $\mathrm{q}_{\mathrm{t}}$ are the amounts of metal ions adsorbed onto the adsorbents $(\mathrm{mg} / \mathrm{g})$ at equilibrium and at time $t$, respectively. $\mathrm{k}_{1}$ is the rate constant of the first order $\left(\min ^{-1}\right)$. By plotting $\log \left(\mathrm{q}_{\mathrm{e}}-\mathrm{q}_{\mathrm{t}}\right)$ versus $\mathrm{t}$, the first-order constant $\mathrm{k}_{1}$ and equilibrium capacity $\mathrm{q}_{\mathrm{e}}$ can be obtained from the slope (negative values) and intercept, respectively.

On the other hand, the pseudo second order model is expressed as:

$$
\mathrm{t} / \mathrm{q}_{\mathrm{t}}=1 / \mathrm{k}_{2} \mathrm{q}_{\mathrm{e}}^{2}+\mathrm{t} / \mathrm{q}_{\mathrm{e}}
$$

Where $\mathrm{k}_{2}$ is the pseudo second order rate constant of adsorption $\left(\mathrm{g} \mathrm{mmol}^{-1} \mathrm{~min}^{-1}\right)$. The aforementioned two models basically consider external film diffusion, interaparticle diffusion and interaction step for adsorption process. The rate determining step of the adsorption reaction may be one of the above three steps. The external film diffusion is eliminated by stirring. So, the adsorption rate may be controlled by intraparticle diffusion or interaction step. The kinetic parameters for the pseudo 
first and pseudo second models are determined from the linear plots of $\log \left(\mathrm{q}_{\mathrm{e}}-\mathrm{q}_{\mathrm{t}}\right) \mathrm{vs} \mathrm{t}$ (Fig. 6b) or (t/qt) vs $t$ (Fig. 6c), respectively. The validity of each model could be checked by the fitness of the straight lines ( $\mathrm{R}^{2}$ values). Accordingly as shown in Table 2 .

Table 2: Kinetic parameters (pseudo-first and second order) for the adsorption of $\mathrm{Fe}^{2+}$ resin.

\begin{tabular}{|c|c|c|c|c|}
\hline Metal ions & qe (mg/g) Theoretical & qe (mg/g) practical & $K_{1}\left(g /(m g \quad m i n) \times 10^{-3}\right.$ & $\mathbf{R}^{2}$ \\
\hline \multirow{5}{*}{$\mathrm{Fe}^{2+}$} & \multicolumn{4}{|c|}{ Pseudo-first order } \\
\hline & 8.89 & 26.3 & 1.2 & 0.97 \\
\hline & \multicolumn{4}{|c|}{ Pseudo-second order } \\
\hline & qe $(\mathrm{mg} / \mathrm{g})$ Theoretical & qe $(\mathrm{mg} / \mathrm{g})$ practical & $\mathrm{K}_{2}\left(\mathrm{~g} /(\mathrm{mg} \min ) \times 10^{-3}\right.$ & $\mathbf{R}^{2}$ \\
\hline & 31.28 & 26.3 & 6.9 & 0.99 \\
\hline
\end{tabular}

The adsorption of $\mathrm{Fe}^{2+}$ on the resin is perfectly fit pseudo second order model rather than pseudo first order one. In addition, the experimental and theoretical values of qe (obtained from pseudo second order model) are closely similar, confirming the validity of that model to the adsorption system under consideration. This implies that the rate determining step of the adsorption reaction depends on both the concentration of the active sites and the textural properties of the resin.

\section{Determination of adsorption isotherms}

Equilibrium sorption isotherms (capacity studies) are of fundamental importance in the design of adsorption systems since they indicate how metal ions are partitioned between the adsorbent and liquid phases at equilibrium as a function of metal concentration. When an adsorbent comes into contact with a metal ion solution, the concentration of metal ions on the surface of the adsorbent will increase until a dynamic equilibrium is reached; at this point, there is a clearly defined distribution of metal ions between the solid and liquid phases. Iron ion concentrations with a varied temperatures and $\mathrm{pH}$. As metal concentration increased, the removal efficiencies decreased. Thus, increasing the initial metal concentrations in the solutions decreased the removal efficiency. It is likely that a given mass of adsorbent material has a finite number of adsorption sites, and that as metal concentrations increase, these sites become saturated. That is, there is some metal concentration that produces the maximum adsorption for a given adsorbent mass, and thereafter, adding more metal cannot increase adsorption because no more sites are available: all are occupied. Another cause may have been a progressive decrease in the proportion of covalent interaction and an increase in the proportion of electrostatic interactions at sites with a lower affinity for metals as the initial metal concentrations increased. The Langmuir, Freundlich isotherms are commonly used for wastewater treatment applications. Langmuir equation was developed by Langmuir in 1916 to describe the adsorption of gas molecules on a planar surface. The Langmuir model suggests, as a hypothesis, that uptake occurs on a homogenous surface by monolayer sorption without interaction between sorbed molecules. The Langmuir equation has the form:

$\mathrm{C}_{\mathrm{e}} / \mathrm{q}_{\mathrm{e}}=\left(1 / \mathrm{Q}_{\mathrm{o}} \cdot \mathrm{K}_{\mathrm{L}}\right)+\left(1 / \mathrm{Q}_{\mathrm{o}}\right) \mathrm{C}$

(Davila et al., 2005)

where $\mathrm{q}_{\mathrm{e}}$ is the amount adsorbed at equilibrium $(\mathrm{mg} / \mathrm{g}), \mathrm{C}_{\mathrm{e}}$ the equilibrium concentration $(\mathrm{mg} / \mathrm{L})$, $\mathrm{b}$ is a constant related to the rate of adsorption $(\mathrm{L} / \mathrm{mg})$, and $\mathrm{Q}_{0}$ is the maximum adsorption capacity (mg/g).

By plotting $\left(\mathrm{C}_{\mathrm{e}} / \mathrm{q}_{\mathrm{e}}\right)$ versus $\mathrm{C}_{\mathrm{e}}, \mathrm{q}_{\mathrm{m}}$ and $\mathrm{b}$ can be determined if a straight line obtained Fig. (6d). The freundlich model assumes a heterogeneous adsorption surface with sites that have different energies of adsorption and are not equally available. The freundlish isotherm is more widely used but provides no information on the monolayer adsorption capacity and can be written as:

$\log \mathrm{q}_{\mathrm{e}}=\log \mathrm{K}_{\mathrm{f}}+(1 / \mathrm{n}) \log \mathrm{C}_{\mathrm{e}}$

(Noroozi et al., 2007)

where $\mathrm{q}_{\mathrm{e}}$ is the amount adsorbed at equilibrium $(\mathrm{mg} / \mathrm{g})$ and $\mathrm{C}_{\mathrm{e}}$ is the equilibrium concentration $(\mathrm{mg} / \mathrm{L}) . \mathrm{K}_{\mathrm{F}}$ and $\mathrm{n}$ are equilibrium constants indicative of adsorption capacity and adsorption intensity, respectively. In general, as the $\mathrm{K}_{\mathrm{F}}$ value increases, the adsorption capacity of the adsorbent, for the given adsorbate, increase, $\mathrm{n}$ values between 1 and 10 show beneficial adsorption. If $\mathrm{n}$ is close to 1 , the 
surface heterogeneity could be assumed to be less significant and as $\mathrm{n}$ approaches 10 the impact of surface heterogeneity becomes more significant (Davila et al., 2005).

By applying the different isotherm models (Langmuir and Freundlish) on the sorption of $\mathrm{Fe}^{2+}$ on crosslinking PVA/TNT are shown in Figs. (6d,6e). Parameters related to each isotherm were determined by using linear regression analysis and the square of the correlation coefficients $\left(\mathrm{R}^{2}\right)$ have been calculated. A list of the parameters obtained together with $\mathrm{R}^{2}$ values is provided in Table (3). It has been found that the best fitted isotherm equation was Freundlich with $\mathrm{R}^{2}=(0.988)$. The parameter of the freundlich equation reveals that the adsorption sites have narrow energy distribution. Since its value was close to 1(Noroozi et al., 2007). The correlation coefficient of Langmiur isotherm equation is lower than that obtained for the Freundlich equation. Although the Langmiur equation describes adsorption on strongly homogeneous surfaces, which is not the case of our adsorbents because they exhibit a chemical heterogeneity as represented by different functional groups, however, the $\mathrm{n}$ parameter of the Freundlich adsorption equation reveals adsorption sites with low energetically heterogeneity of this adsorbent ${ }^{[25]}$. Based on this reason it can be seen from the obtained data the langmiur equation can be fitted with a describle $\mathrm{R}^{2}=0.974$ with a monolayer capacity are suitable than other reported natural adsorbents (Donia et al., 2007).

Table 3: Regression parameters for the Langmuir and Freundlich isotherms for solutions of $\mathrm{Fe}^{2+}$

\begin{tabular}{lcccccc}
\hline \multirow{2}{*}{ Metal } & \multicolumn{2}{c}{ Langmuir constants (Resin) } & \multicolumn{3}{c}{ Freundlich constants (Resin) } \\
\cline { 2 - 6 } & $\mathbf{Q}_{\mathbf{0}}(\mathbf{m g} / \mathbf{g})$ & $\mathbf{K}_{\mathbf{L}}$ & $\mathbf{R}^{\mathbf{2}}$ & $\mathbf{K}_{\mathbf{F}}$ & $\mathbf{n}$ & $\mathbf{R}^{\mathbf{2}}$ \\
\hline $\mathrm{Fe}(\mathrm{II})$ & 55.56 & 0.114 & 0.974 & 1.18 & 0.813 & 0.988 \\
\hline
\end{tabular}

\section{Regeneration studies}

Regeneration of the spent adsorbent is necessary to restore its original adsorption capacity and it enables valuable metals to be recovered from wastewater streams for reuse. In this study, $\mathrm{Fe}(\mathrm{II})$ was desorbed from Ti-PVA using $2 \mathrm{M}$ HNO3. From (Fig. 5f) we can suggests that the regeneration efficiency of adsorbent was almost complete for the metal. These results indicate the suitability of $\mathrm{HNO}_{3}$ as the regenerant for the adsorbent. It seems that Ti-PVA stabilized to resist acidic regenerate.

\section{Application}

In Bahr El-Baqar, all localities depend on groundwater as one of the main water supplies for different purposes (human, animals drinking, and irrigation).The groundwater in the study area is obtained from the Quaternary aquifer. From the chemical analysis of the Quaternary groundwater it is clear that, the soluble iron, of some samples is more than the permissible limit $(0.3 \mathrm{mg} / 1)$. To overcome this problem, two contaminated groundwater samples of the Quaternary groundwater (by soluble iron) were chosen for the treatment process. The efficiency of the treatment was measured by chemical analysis of such 19 groundwater samples before and after this process using Ti/PVA. It was found that the soluble iron in samples number 11 and was $0.382 \mathrm{ppm}$ before treatment and $0.079 \mathrm{ppm}$ after treatment, and $0.4386 \mathrm{ppm}$ before treatment and $0.157 \mathrm{ppm}$ after treatment .It can be concluded that the surfaces of Ti/PVA had adsorption sites that were able to bind Fe(II) ions.

\section{Conclusions}

In this study we prepare crosslinking Ti / PVA beads which can be easily utilized in heavy metal adsorption and collection. SEM and FTIR revealed that the crosslinking Ti / PVA possessed the structure which could contribute to high activity. The results of our compound studies implied that the prepared compound was employed well to adsorb metal ions in solutions. Also the kinetic data were better described by the pseudo-second-order model than by the pseudo-first-order model. The equilibrium adsorption data were analyzed with isotherm models (Langmuir model, Freundlich model) the study showed that our compound has high potential for removing heavy metals from polluted water. In conclusion, the prepared crosslinking Ti / PVA composite showed excellent adsorption capacity for the adsorption of heavy metal ions. Therefore, the crosslinking Ti / PVA can be a potential candidate for various applications including removal of heavy metal ions or synthesis of crosslinking Ti / PVA composite. 


\section{References}

Abdelrazek, S.A. 2019. Monitoring Irrigation Water Pollution of Nile Delta of Egypt with Heavy Metals. Alexandria Science Exchange Journal, 40(3):441: 450.

Dahab, K.A., E.A. El Abd, M.K. Fattah, and M.M. El Osta 2007. Assessment of groundwater problems of the Quaternary aquifer in the area between El Salhia El Gidida-Abu Sweir, East Nile Delta. Egypt Gremna., 2: 329-353.

Davila-Jimenez, M.M., M.P. Elizalde-Gonzalez and A.A. Pelaez-Cid. 2005. Adsorption interaction between natural adsorbents and textile dyes in aqueous solution, Colloids Surf. A 254: 107-114.

Desouky, A.M., 2018. Remove heavy metals from groundwater using carbon nanotubes grafted with amino compound. Journal of separation science and technology, 53(11).

Donia, A., A.A. Asem and Z.E. Khalid 2007. Recovery of gold(III) and silver(I) on a chemically modified chitosan with magnetic properties- Chemistry Department, Faculty of Science, Menoufia University, Shebin El-Kom, Egypt Hydrometallurgy 87:197-206.

Eissa, M., M. Ali, E. Zaghlool and O.S. Stash, 2019. Hydrochemical and stable isotopes indicators for detecting sources of groundwater contamination close to Bahr El-Baqar drain, eastern Nile Delta, Egypt. Water Science, 33(1): 54-64

El Arabi, N., Y. Idris and A. Fekry, 2013. Temporal and Spatial Change Detection of Variations in the Groundwater Composition by Multivariate Statistical Techniques. New York Science Journal, $3 ; 6(11): 31-48$.

El Saliby, I., 2012. Photoreactive Titanate Nanomaterials for Water Purification Systems. Faculty of Engineering and Information Technology University of Technology, Sydney Australia. PhD.

El-Eweddy, E.A.I., 2000. Factors Affecting the Accumulation Rate of Pollutants in Desert Soils under the Condition of Irrigation with El-Salam Canal Waters, Ph.D. Thesis, Agricultural Sciences, Minufiya University.

El-Kiki, M., 2018. Environmental Impact of Water Reuse Of Bahr El-Baqar Drain. State of the Art Report. Civil Engineering Department, Faculty of Engineering, Port Said University.

Gad M.I., 1995. Hydrogeological studies for groundwater reservoirs, east of the Tenth of Ramadan city and vicinities. a master thesis submitted to Ain Shams Uni, Cairo, Egypt(1995).

Geriesh, M.H., 1994. Hydrogeological and hydrogeochemical evaluation for the groundwater resources in the Suez Canal region, Egypt. (Ph. D. Thesis), Fac. Sci., Suez Canal Univ. Egypt.

Gomaah, M., T. Meixner, E.A. Korany, H. Garamoon, and M.A. Gomaa, 2016. Identifying the sources and geochemical evolution of groundwater using stable isotopes and hydrogeochemistry in the Quaternary aquifer in the area between Ismailia and El Kassara canals, Northeastern Egypt. Arabian Journal of Geosciences, 9(6).

Huiyuan, L., L. Guangxia, W. Jie, Z. Xin and Z. Hui, 2015. Removal of tetracycline from aqueous solution by hydrothermal method derived titanate nanotubes. Desalination and Water Treatment, 57(42): 19965-19974

.Lee, C.K., C.C. Wang, L.C. Juang, M.D. Lyu, S.H. Hung, and S.S. Liub. 2008. Effects of sodium content on the microstructures and basic dye cation exchange of titanate nanotubes. Colloids and Surfaces A: Physicochemical and Engineering Aspects, 317(1-3): 164-173

.Lee, C.K. K.S. Lin, C.F. Wu, M.D. Lyu, C.C. Lo. 2008a. Effects of synthesis temperature on the microstructures and basic dyes adsorption of titanate nanotubes, J. Hazard. Mater., 150: 494503.

Lee, C.K., S.S. Liu, L.C. Juang, C.C. Wang, M.D. Lyu, and S.H. Hung. 2007. Application of titanate nanotubes for dyes adsorptive removal from aqueous solution, J. Hazard. Mater. 148: 756-760.

Liu, W.T.W., A.G.L. Borthwick, Y. Wang, X. Yin, X. Li, and J. Ni. 2013. Adsorption of $\mathrm{Pb}^{2+}, \mathrm{Cd}^{2+}$, $\mathrm{Cu}^{2+}$ and $\mathrm{Cr}^{3+}$ onto titanate nanotubes: Competition and effect of inorganic ions, Sci. Total Environ. 456-457: 171-180.

Moussa, B.M., 1990. Petrology and soil genesis of the surface Quaternary deposits, East of the Nile Delta, Egypt. A PhD thesis submitted to the Uni. of Ain shams. Faculty of Sci.

Mranda, T., A.R. Goncalves and M.T. Pessoa, 2001. Ultraviolet-induced crosslinking of poly(vinyl alchol) evaluated by principal component analysis of FTIR spectra, polymer international, 1068-1072 
Niu, H.Y., J.M. Wang, Y.L. Shi, Y.Q. Cai, and F.S. Wei, 2009. Adsorption behavior of arsenic onto protonated titanate nanotubes prepared via hydrothermal method. Microporous and Mesoporous Materials, 122(1-3): 28-35.

Noroozi, G.A.S, H. Bahrami and M. Arami, 2007. Equilibrium and kinetic adsorption study of a cationic dye by natural adsorbent- Silkworm Pupa, J. of Hazardous materials, B139: 167-174.

Pająk, J., Z.I.E.M.S.K.I. Michał, and N.O.W.A.K. Bożena 2010. Poly(vinyl alcohol) - biodegradable vinyl material Faculty of Biology and Environmental Protection, University of Silesia, Katowice, Science Technique, 64: 7-8, 523-530

Peppas, N.A., Y. Huang, M. Torres-Lugo, J.H. Ward, and J. Zhang. 2000. Physicochemical Foundations and Structural Design of Hydrogels in Medicine and Biology. Annual. Rev. Biomedical Engineering, 2:9-29.

Qu, X.L., J. Brame, Q. Li, and J.J.P. Alvarez, 2013. Nanotechnology for a safe and sustainable water supply: enabling integrated water treatment and reuse. Accounts of Chemical Research 46 (3) : 834-843

RIGW-IWACO., 1992. Hydrogeological map of Egypt, 1:2000,000. Cairo, Egypt: Research institute for groundwater.

Rocío, T., R. Espinoza-González, F. Gracia, F. Rodrigues, P. Ubirajara, M. Flores, E. Sacari, 2019. As(III) Removal from Aqueous Solution by Calcium Titanate Nanoparticles Prepared by the Sol Gel Method. Nanomaterials, 9(5): 733.

Sheng, G.B.Hu, 2013. Role of solution chemistry on the trapping of radionuclide Th(IV) using titanate nanotubes as an efficient adsorbent, J. Radioanal. Nucl. Chem., 298: 455-464.

Sheng, G.H.D., R. Shen, and Y. Li. 2013. Microscopic insights into the temperature-dependent adsorption of Eu(III) onto titanate nanotubes studied by FTIR, XPS, XAFS and batch technique, Chem. Eng. J. 217 : 486-494.

Sheng, G.L.Y., Y. Li, H. Dong, H. Li, X. Gao, and Y. Huang, 2014. EXAFS study of the interfacial interaction of nickel (II) on titanate nanotubes: Role of contact time, $\mathrm{pH}$ and humic substances. Chemical Engineering Journal, 248: 71-78.

Xie, A., J. Dai, J. Cui, J. Lang, M. Wei, X.-H. Dai, C. Li, and Y. Yan, 2017. Novel Graphene OxideConfined Nanospace Directed Synthesis of Glucose-Based Porous Carbon Nanosheets with Enhanced Adsorption Performance. ACS Sustainable Chemistry \& Engineering, 5(12): 1156611576.

Xiong, L.Y.Y., J. Mai, W. Sun, C. Zhang, D. Wei, Q. Chen, and J. Ni. 2010. Adsorption behavior of methylene blue onto titanate nanotubes. Chemical Engineering Journal, 156(2): 313-320.

Xiong, L.C.C., Q. Chen, J. Ni. 2011. Adsorption of Pb(II) and Cd(II) from aqueous solutions using titanate nanotubes prepared via hydrothermal method, J. Hazard. Mater. 189: 741-748. 